8th International Conference on Physical and Numerical Simulation of Materials Processing (ICPNS)

14-17 October 2016

Seattle, Washington | Hosted by Purdue University

SESSION 5: IRON AND STEEL, HARBOR HALL

Co-Chairs: Xixiang Zhang, King Abdullah University of Science and Technology; Jianming Gong, Nanjing Tech University

SUNDAY, OCTOBER 16, 2016

\title{
Application of numerical simulation during the development of ductile iron bearing seat
}

Ping Li; YanjieZhao; Junquan Wei, Jitai Niu, Henan Polytechnic University; Fengjun Li, China Yituo Group Co., Ltd.

\begin{abstract}
The study deals with the casting defects of shrinkage and dispersed shrinkage appeared during the development of ductile iron bearing seat due to the original process of conventional side-riser feeding on the basis of general casting design method. The bearing seat was cast using automatic air-impact molding production line with green sand. The commercial software InteCAST was used to simulate casting solidification process and to analyze the reason for the casting defects. Furthermore, the optimized process was proposed in conjunction with three pieces of arc-type chills and a side-rider every casting. The result of mass production shows that the casting defects of bearing seat were effectively eliminated by the optimized process. Consequently, the development cycle of bearing seat was significantly shortened and business opportunities of new market are obtained for the foundry enterprise.
\end{abstract}

KEYWORDS: bearing seat, ductile iron, numerical simulation, solidification, casting defect 